\title{
Relação dialética no processo ensino-aprendizagem: desafios à formação docente
}

\author{
Maria Elizabete Neves Ramos
}

Pontifícia Universidade Católica, Rio de Janeiro, RJ, Brasil

Ana Cristina Prado de Oliveira

Universidade Federal do Estado do Rio de Janeiro, Rio de Janeiro, RJ, Brasil

Resumo

Em um contexto que denuncia uma situação grave no cenário educacional (altas taxas de reprovação e abandono e baixos resultados acadêmicos em testes de larga escala), lança-se a questão: por que nossas crianças e jovens não estão aprendendo o que deveriam quando deveriam? Este ensaio, propondo uma articulação entre os campos da psicologia, sociologia e filosofia educacional, traz uma análise sobre como educadores vêm compreendendo o processo de ensino-aprendizagem nos contextos escolares a partir de uma revisão de literatura de como a formação de professores poderia atuar para favorecer aos futuros professores práticas que possibilitem uma aprendizagem interativa e significativa para todos.

Palavras-chave: Ensino; Aprendizagem; Formação docente.

\begin{abstract}
Dialetic relationship in the teaching-learning process: challenges to teacher training

In a context that denounces a critical situation in the educational setting (high rates of failing and dropping out and low academic results in large-scale tests), the question arises: why aren't our children and teenagers learning what they should when they should? This essay, proposing a link between the fields of psychology, sociology and educational philosophy, provides an analysis on how educators have been understanding the teaching-learning process in school contexts and how teacher training could act to enable future teachers with practices that make possible an interactive and meaningful learning for all.
\end{abstract}

Keywords: Teaching; Learning; Teacher training.

${ }^{*} \mathrm{O}$ presente trabalho foi realizado com apoio da Coordenação de Aperfeiçoamento de Pessoal de Nível Superior - Brasil (Capes) - código de financiamento 001. E contou também com o apoio do CNPq. 
Relación dialética en el proceso de enseñanza y aprendizage: desafíos para la formación docente En un contexto en el que traiciona una situación agravante en el entorno educativo (altas tasas de repetición y deserción y los bajos resultados académicos en las pruebas a gran escala) lanza la pregunta: ¿por qué nuestros niños y jóvenes no están aprendiendo lo que les corresponde cuando deberían hacerlo? En este ensayo se propone un vínculo entre los campos de la psicología, la sociología y la filosofía de la educación, aporta un análisis de cómo los educadores comprenden el proceso de enseñanza-aprendizaje en contextos escolares y la forma en que la formación del profesorado podría actuar para promover los profesores futuros con prácticas para permitir un aprendizaje interactivo y significativo para todos.

Palabras clave: Enseñanza; Aprendizaje; Formación de maestros.

A prática educativa na escola tem como um de seus objetivos centrais a socialização dos conhecimentos escolares. As diversas formas pelas quais os professores ensinam e os alunos aprendem refletem diferentes concepções sobre as relações com o saber estabelecidas na escola. Citando Develay, Monteiro (2007) considera: "tanto numa pedagogia que valoriza a ação docente de ensino do professor, como naquela em que o professor é visto como um mediador da aprendizagem dos alunos, sempre existem conteúdos a serem apropriados" (p. 123). Podemos considerar, assim, que a formação docente deveria oferecer algumas contribuições a essa prática ao analisar as relações mantidas pelos agentes envolvidos no processo de ensinar e aprender. Contudo, ainda se mostra um desafio garantir padrões mínimos para a formação inicial dos professores, especialmente nas séries iniciais da educação básica. Esse texto pretende transitar por essas considerações diante de um cenário em que a repetência - entendida como não aprendizagem - ainda se constitui como principal impedimento para a universalização da conclusão do ensino fundamental no Brasil. Pretendemos, assim, trazer luz sobre a importância da formação docente para a realização de práticas educativas intencionalmente mais interativas e eficazes, com o objetivo de garantir uma distribuição mais equitativa dos saberes escolares.

O texto está dividido em cinco seções. A primeira, introdutória, apresenta uma breve contextualização do cenário educacional brasileiro, propondo uma discussão sobre a compreensão dos indicadores de qualidade, lançando como questão: por que algumas crianças não aprendem? A segunda seção discute diferentes concepções sobre o processo de ensino-aprendizagem, propondo uma leitura dialética desse processo a partir da corrente sócio histórica e da relevância dos processos interativos para a efetivação da aprendizagem. A terceira seção apresenta algumas considerações 
sobre esse processo interativo na construção do saber, propostas por Charlot (2000), além de apresentar os resultados de algumas pesquisas nacionais e internacionais que se dedicaram a estudar o tema. A quarta seção discute o papel do professor e sua formação inicial, apresentando alguns dados e desafios para o campo. A quinta e última seção traz nossas considerações finais, destacando algumas questões para a agenda do campo da formação de professores.

\section{Introdução: contexto e discussão}

Sabemos que um sistema educacional considerado eficaz é aquele em que o aluno aprende, passa de ano e conclui a educação básica (FONTANIVE, KLEIN, 2009). Passar de ano e concluir a educação básica é consequência do aprendizado, afinal a passagem pela escola só tem sentido quando se supõe que se sairá dela diferentemente da forma como entrou. Assim, que relação pode ser estabelecida entre a qualidade educacional e a aprendizagem efetiva do aluno no contexto escolar?

Qualidade educacional é um termo polissêmico e comumente adotado, assumindo diferentes definições dependendo do contexto em que é empregado. A Constituição Federal de 1988, buscando ressaltar a garantia do direito social à educação, em seu Art. 206, incisos I e VII, apresenta como princípios basilares da educação nacional "igualdade de condições para o acesso e permanência na escola" e "a garantia de padrão de qualidade” (BRASIL, 1988). O documento não deixa claro, contudo, como se estabelece e mensura tal “padrão de qualidade”. Mas estabelece, em seu Art. 14, o Plano Nacional de Educação, legislação decenal que teria entre seus objetivos a "melhoria da qualidade educacional”. Já a Lei de Diretrizes e Bases da Educação Nacional (LDBEN) n 9.394/96 (BRASIL, 1996) apresenta, de forma um pouco mais detalhada, como esta "garantia de qualidade” está prevista. Em seu Art. $4^{\text {o }}$, inciso IX, estabelece como dever do estado a garantia da oferta, na educação pública, de "padrões mínimos de qualidade de ensino, definidos como a variedade e quantidade mínimas, por aluno, de insumos indispensáveis ao desenvolvimento do processo de ensino-aprendizagem”. As discussões sobre quais seriam esses “insumos indispensáveis” tem norteado as recentes reflexões e trabalhos acerca da construção da Base Nacional Comum Curricular. Atualmente, avaliações externas têm levantado medidas de desempenho dos alunos das escolas públicas em todo o território nacional em testes de Língua Portuguesa e Matemática, entendendo que o acesso à leitura e à resolução de problemas compõem os “insumos indispensáveis” para a 
progressão escolar. Tais levantamentos, associados a dados contextuais referentes às escolas e aos alunos, trazem para o campo educacional novas possibilidades de reflexões sobre a questão da qualidade educacional.

Desenvolvendo um levantamento histórico, Oliveira e Araújo (2005) apontam três distintos significados que a expressão qualidade da educação assumiu ao longo da história da educação no Brasil: acesso à escola, fluxo e desempenho escolares. As políticas educacionais refletem estas associações, definindo a agenda de prioridades para as redes de ensino e o papel esperado dos gestores e agentes educacionais nos últimos anos. Tendo em vista a recente universalização das possibilidades de acesso ao ensino fundamental no Brasil, as atenções se voltam para a permanência, fluxo e aprendizagem dos alunos no contex to escolar.

A alta taxa de reprovação é problema de longa data na educação brasileira. Diversos pesquisadores (KLEIN, 2006; OLIVEIRA, ARAÚJO, 2005) concordam que um dos maiores e mais crônicos problemas do ensino brasileiro é a repetência, que se expressa não apenas nas elevadas taxas de reprovação, mas também na defasagem idade-série (CORREA et al., 2014).

Gráfico 1. Taxas de reprovação no Ensino Fundamental e Médio, 2010-2017.

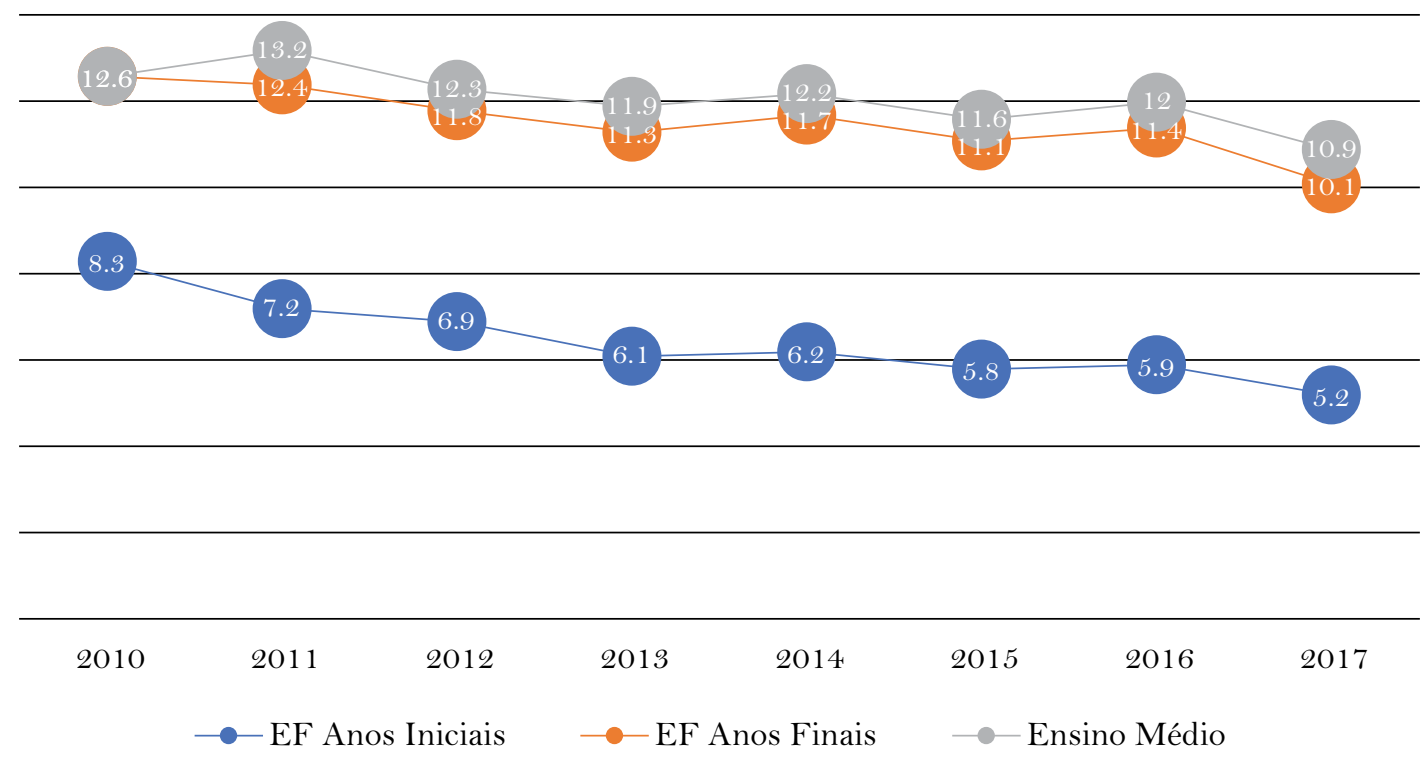

Fonte: Produzido pelas autoras com base nos dados disponibilizados pela Plataforma Educacional Qedu, (www.qedu.com.br, acessado em 14/05/2019). 
Gráfico 2. Taxas de abandono no Ensino Fundamental e Médio, 2010-2017.

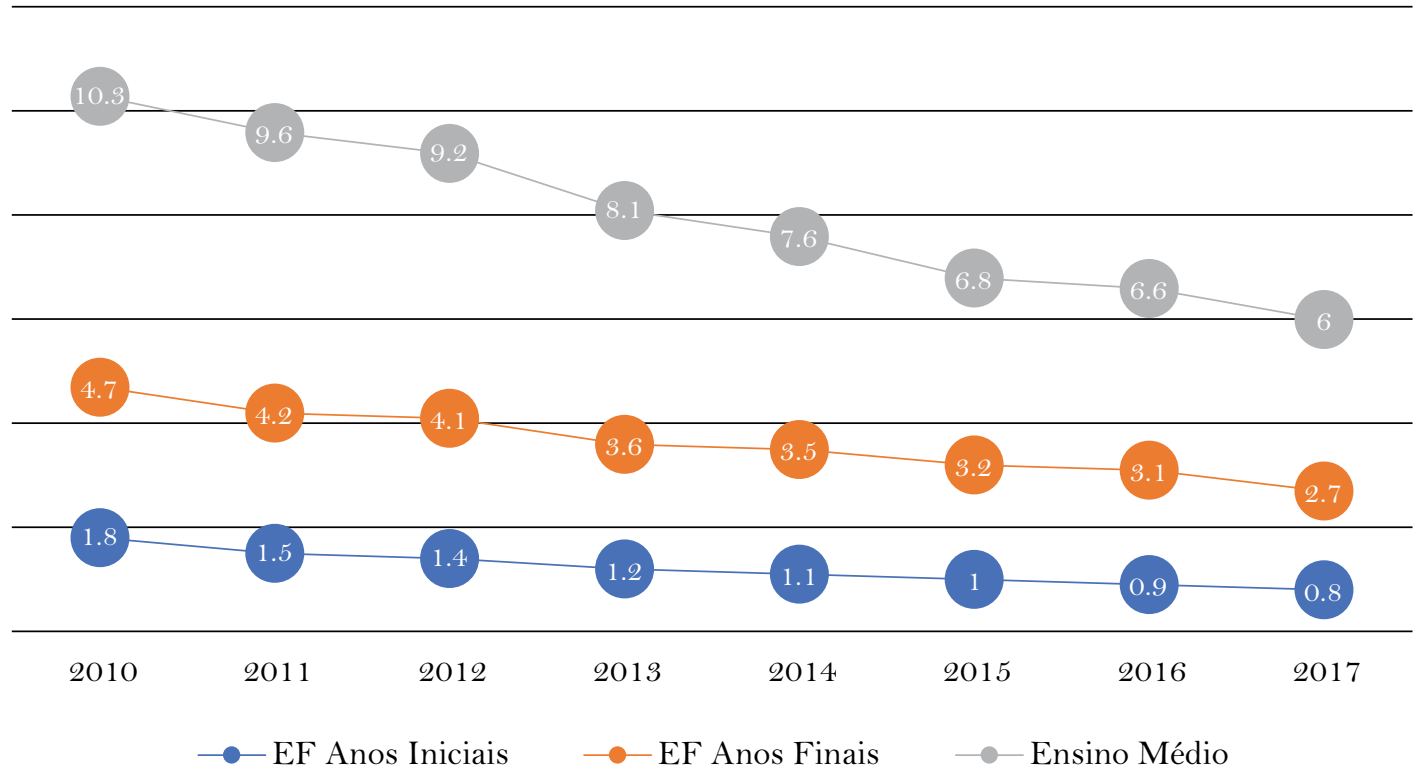

Fonte: Produzido pelas autoras com base nos dados disponibilizados pela Plataforma Educacional Qedu, (www.qedu.com.br, acessado em 14/05/2019).

Conforme mostram os dados apresentados nos Gráficos 1 e 2 , há uma visível involução nas taxas de abandono nos dois níveis educacionais e a diminuição da taxa de reprovação no ensino fundamental nos últimos anos. Ainda assim, a não aprovação por reprovação ou por abandono encontra atualmente (2017) altos índices no país: 6,0\% nos anos iniciais, $12,8 \%$ nos anos finais do ensino fundamental e 16,9\% no ensino médio.

Estes elevados índices nos mostram que, apesar de terem garantido seu direito de acessar a escola básica, nem todos os alunos estão avançando adequadamente em sua trajetória escolar, seja porque são reprovados ou porque abandonam a escola (ou uma conjunção dos dois fatores). De acordo com Ribeiro (1991), a repetência tende a provocar novas repetências, ao contrário do que sugere a cultura pedagógica brasileira de que repetir ajuda a criança a progredir em seus estudos. As consequências do processo de retenção da população nas primeiras séries do ensino fundamental são de tal magnitude que os indivíduos ficam velhos em relação à série que ainda estão cursando e tendem a abandonar a escola (SOARES, 2007, p. 138). A taxa distorção idade-série (proporção de alunos com atraso escolar de 2 anos ou mais), ainda bastante alta em nosso país (11\% em 2018), retrata uma situação de fracasso... Os alunos não progridem nos anos de escolarização por não aprenderem o esperado para a sua faixa etária ou pelo reforço de uma cultura da reprovação? E, se não aprenderam o que deveriam ter aprendido, por que isso aconteceu? 
A preocupação com o chamado "fracasso escolar" deu origem a inúmeras pesquisas. Patto (1996), com base em ampla revisão de literatura, mostra que as explicações dadas para esse "fracasso" apresentam diferentes ênfases, sejam as deficiências do aluno (de origem médica ou psicológica), os fatores intraescolares ou a carência cultural do ambiente em que vive. A repetência escolar é um fenômeno social complexo em cuja produção as características da escola, do aluno e da família interagem. Propomo-nos, então, a analisar as características da escola - especialmente aquelas relacionadas ao processo ensino-aprendizagem - com consequências para a trajetória escolar do alunado.

As pesquisas sobre escolas eficazes têm apontado que, se o background familiar tem um peso importante na definição do desempenho acadêmico do aluno, alguns fatores intraescolares poderiam minimizar o efeito da origem social, promovendo a eficácia e a equidade na oferta educacional (BROOKE, SOARES, 2008). Autores que buscaram mensurar o efeito dos fatores intraescolares indicam que entre $10 \%$ e 20\% da variância nos resultados dos alunos poderia ser explicada por aspectos escolares, tendo controlado as variáveis indicativas das características de origem dos alunos (CREEMERS, REEZGIT, 1996, p. 203). No campo da pesquisa educacional nacional, esta discussão é mais recente. Alves e Franco (2008) sintetizam quais seriam os fatores intraescolares associados à eficácia escolar nos estudos nacionais: Recursos escolares; Organização e gestão da escola; Clima acadêmico; Formação e Salário docente; Ênfase pedagógica (op. cit., p. 494, grifos das autoras). As pesquisas nesta linha têm buscado, assim, evidenciar como o trabalho nas escolas poderia favorecer a aprendizagem de todas as crianças, independentemente de sua origem social. No contexto educacional brasileiro, compreender este processo se faz urgente, uma vez que um consenso é claro: nossas crianças e adolescentes não estão aprendendo como, quanto e quando deveriam. Neste estudo, destacamos os dois últimos fatores considerados pelos autores que estão relacionados ao trabalho docente na condução do processo ensino-aprendizagem.

Nesta seção apresentamos uma análise do contexto educacional nacional, que revelam indicadores de trajetória escolar preocupantes, ressaltando as dificuldades encontradas na condução de políticas educacionais que garantam uma distribuição mais equitativa da aprendizagem escolar. Para aprofundar a discussão, pretendemos considerar alguns aspectos relevantes no tocante à maneira como a criança aprende, processo em que o papel do professor é fundamental. Assim, consideraremos nas se- 
ções que se seguem as concepções sobre o processo ensino-aprendizagem, as relações que os sujeitos, em interação, constroem com o "saber” e discutiremos sobre a necessidade de uma formação docente para atuar nesta construção.

\section{Ensino-aprendizagem}

O processo de ensino e aprendizagem pode ser entendido de diversas formas. O entendimento de como os indivíduos aprendem ou se desenvolvem acarreta desdobramentos na prática pedagógica da escola e do professor.

Em uma perspectiva cognitivista do processo ensino-aprendizagem, Piaget demonstrou que existem formas de perceber, compreender e se comportar diante do mundo, próprias de cada faixa etária. Castorina (2002) observa que a aprendizagem, para Piaget, depende do desenvolvimento de determinadas estruturas que vão possibilitar conhecer o mundo, de forma que é o desenvolvimento dessas capacidades cognitivas que vai possibilitar a aprendizagem. Portanto, a aprendizagem seria decorrente do próprio desenvolvimento.

Vygotsky, no entanto, entende que a aprendizagem é que produz o desenvolvimento, acentuando o foco na interação do sujeito com o meio, destacando a importância da mediação. Em sua concepção, o conhecimento está no mundo e é ele que move o desenvolvimento; o conhecimento vem da mediação cultural e a partir daí a criança vai se desenvolvendo (VYGOTSKY, 2008). Os fenômenos da linguagem e do pensamento são compreendidos dentro do processo sócio-histórico e, por esse motivo, Vygotsky afirma que a aprendizagem dos conceitos deve partir das práticas sociais, evidenciando a necessidade de contextualizar o ensino. Para ele, os processos de desenvolvimento e de aprendizagem estão intimamente relacionados e essa relação é dialética.

De acordo com Vygotsky (2009), a aprendizagem se dá nas relações com outros homens, nas quais se transmitem intencionalmente os conhecimentos produzidos historicamente. A criança se desenvolve a partir do meio sociocultural, considerando o que lhe é disponibilizado e oferecido para desenvolver-se ou não. Portanto, é necessário recuperar o papel do educador como aquele que planeja a ação educativa para promover o desenvolvimento de seus alunos. $\mathrm{O}$ conhecimento, devido à sua complexidade, exige formas também sistematizadas para sua apropriação e não se dá de modo espontâneo. Por esse motivo, o professor deve ser o organizador do meio social 
(VYGOTSKY, 2001). Assim, o conhecimento é compreendido como uma construção social, pois tem origem relacional e discursiva.

A criança é um agente na sua própria construção e na construção do mundo, mas, como destaca Wartofsky (1999), um agente cuja ação se desenvolve no contexto de uma prática social e histórica. No enfoque dessa interação entre a criança e o mundo, seu contexto histórico e social sempre presente, acentua o caráter dialético. Devido a sua complexidade, o sentido do termo dialético corresponde a essa interação entre a criança e o mundo, considerando que o conhecimento se forma e se transforma pela interação de ambos. A importância da presença do outro na construção do conhecimento é entendida na perspectiva histórico-cultural, em que o papel central é desempenhado pela linguagem. A dialética, assim, tem uma dimensão dialógica, que se reflete em vários aspectos, como por exemplo, na forma de avaliar, em que muitas vezes as perguntas são formas retóricas que não contemplam a dimensão dialógica. Kramer (2003) afirma que muitas atividades buscam simplesmente saber se as crianças sabem repetir as respostas; não são questões, mas um convite à memorização, pois não estimulam o pensamento nem a criatividade. A dimensão dialética também diz respeito à própria concepção de currículo, cuja hegemonia é produzida e reproduzida pelo aspecto formal do conhecimento escolar, e, ao contrário do que parece, nem sempre é marcado pelo consenso. Uma dimensão dialética do currículo é a que percebe a "realidade” da sociedade como conflito e fluxo em vez de um “sistema funcional fechado”. Na maioria das escolas os estudantes recebem uma visão que serve para a manutenção do status quo ao se evitar os conflitos e as possibilidades de mudança. Nesse sentido, a educação é também um ato político, o que confere à atuação docente o compromisso de ajudar a pensar. A dimensão dialética também diz respeito à própria concepção de planejamento. Corazza (1997), por exemplo, afirma que a ação pedagógica é uma forma de política cultural, exigindo por isso uma intervenção intencional que é, sem dúvida, de ordem ética. E acrescenta: "ética que implica respeito e responsabilidade para com essa ação e para com os sujeitos dela integrantes" (CORAZZA, 1997, p. 121). É o que a autora chama de didática dialética, na qual o professor, na sua prática de planejar, produz um trabalho pedagógico assumindo suas decisões, e não fica apenas como mero executor de um programa a ser cumprido.

O papel social das crianças e seu desenvolvimento dependem dialeticamente das condições de vida, da classe social e do meio cultural (KRAMER, SANTOS, 2011). Para Vygotsky (2008, p. 109), o processo de internalização da realidade social, da cultura e 
da história, se dá através da linguagem. O papel do outro é central na constituição dos conhecimentos e dos afetos. Para ele, a criança é um ser de cultura, que se constitui na relação com os outros, principalmente pela apropriação da linguagem (KRAMER, SANTOS, 2011). Vygotsky (2008, p.128) afirma que a aprendizagem dos conceitos deve partir das práticas sociais, evidenciando a necessidade de contextualizar o ensino.

De acordo com Prestes (2010), quando na obra de Vygotsky se fala em aprendizagem, o termo correto seria instrução. Não se trata de um entendimento de instrução como transmissão do saber, crítica conhecida ao ensino tradicional, mas de um processo em que atividade da criança é orientada por alguém que tem a intencionalidade de fazê-lo. Ampliando a discussão sobre os reflexos desta atuação na aprendizagem dos alunos, faz-se necessário compreender qual é a influência do tipo de relação construída em sala de aula, com cada um de seus alunos e com a coletividade, no sucesso escolar destes estudantes.

\section{A relação com o saber}

Bernard Charlot, um dos principais teóricos da sociologia da educação a discutir esta questão, ao tratar das relações de saber reforça que estas são relações sociais em sua essência, e sem as quais não há saber (CHARLOT, 2000). Compreende-se, assim, a relação de contínua dependência entre a aprendizagem e as interações sociais, uma vez que o ser humano, como salienta o autor, é essencialmente social.

A discussão sobre os mecanismos/estratégias que se realizam em sala de aula é fundamental para clarear algumas concepções sobre as relações que se estabelecem no ambiente de aprendizagem (especialmente entre professor e aluno), sobre quem é este sujeito que aprende e quais são os elementos que produzem uma situação de fracasso escolar. Portanto, considerando esta dimensão social da aprendizagem, conhecer quais são as influências das diferentes formas de interação do professor com seus alunos nos possibilita localizar e propor intervenções significativas na aprendizagem das crianças.

Alguns pesquisadores em nossa área vêm apresentando resultados de trabalhos investigativos neste sentido, mostrando algumas evidências da influência do tipo de relação construída com o professor no nível de aprendizagem dos alunos. Tacca e Branco (2008), por exemplo, partem de estudos teóricos sobre a perspectiva denominada de sociocultural construtivista e de um trabalho de pesquisa desenvolvido por elas com turmas de $2^{\mathrm{a}}$ série do Ensino Fundamental. O objetivo é tentar compreender 
a relação que se estabelece entre as interações professor-alunos e a aprendizagem. As autoras destacam a relevância de o aluno construir uma autoimagem positiva no seu processo de aprendizagem. E, no espaço da sala de aula, o papel do professor é decisivo nesta construção. É essencial que o professor conheça, então, as características de seu grupo e quais são os mecanismos ou estratégias que mais mobilizam todos ou cada um para a aprendizagem dos conteúdos. Segundo Tacca e Branco (2008), esta tarefa é determinante no planejamento do professor.

Através dos mecanismos de comunicação, os atores sociais, professores e alunos, negociam as direções da construção dos conceitos que devem ser aprendidos. E é como este processo se estabelece e como o professor pode direcioná-lo que as autoras buscaram investigar. Tacca e Branco (2008) evidenciam alguns comportamentos e posturas das professoras que influenciam de maneira categórica na forma como aquelas crianças se relacionam com a atividade e com o que deve ser aprendido.

Em um cenário onde a interação se torna o foco da discussão sobre a aprendizagem, também se tornam decisivas as concepções que cada professor tem sobre o saber e sobre o aluno, pois elas determinarão a natureza da interação.

Uma das perspectivas a serem observadas, para compreender melhor como se dá a interação professor-aluno, é a escolha e utilização das estratégias e recursos metodológicos pelo professor em sala de aula. A opção por um material/estratégia diz muito sobre a concepção teórica daquele educador, mas também sobre o tipo de interação que pretende estabelecer com seus alunos. Para compreender melhor como uma opção metodológica e seu desenvolvimento traduzir-se-ia na aprendizagem dos alunos, Nunes-Macedo et al. (2004) analisaram os resultados de uma pesquisa etnográfica que realizaram em uma turma de primeiro ciclo do Ensino Fundamental. Através da observação e das entrevistas e questionários realizados, os autores detiveram seu interesse na utilização do livro didático enquanto ferramenta de mediação entre o professor e a aprendizagem de seus alunos. A utilização do livro didático como ferramenta central do processo de ensino é uma prática comum nas escolas brasileiras, onde muitas vezes ele determina o planejamento das aulas, sendo a referência principal do professor. Na citada pesquisa, os autores analisaram especificamente como se dá a utilização do livro didático pelas professoras responsáveis pela alfabetização em uma escola. Na observação do cotidiano escolar, foi possível analisar "como as interações na sala de aula foram mediadas pelo livro didático, através do discurso e das vozes que circulam nesse espaço” (NUNES-MACEDO et al., 2004, p. 20). 
Os autores verificaram que a abertura para a participação e discussão coletiva, envolvendo os alunos, muitas vezes revelou a predisposição da professora em ouvir um aluno e ignorar outro. Esta tendência, chamada por alguns teóricos da educação de organização do grupo na lógica centro-periferia (EARP, 2009), aponta para a questão de que alguns alunos são invisibilizados pela professora. Por quê? E qual a consequência desta não escuta para o aluno? Qual a imagem que constrói de si e qual a chance de que volte a tentar apresentar suas ideias e questões? Qual a consequência desta forma de interação em seu resultado acadêmico?

As interações em sala de aula, sobretudo aquelas que se estabelecem entre professor e aluno, constituem também tema de interesse nas comunidades acadêmicas internacionais. Dentre os muitos estudos nesta linha, Mashburn e Pianta (2010) analisam quais são as práticas e programas realmente efetivos para o desenvolvimento emocional e acadêmico de crianças pré-escolares. De acordo com a teoria que embasou a pesquisa, o sujeito está inserido em um sistema ecológico, onde os diferentes níveis se complexificam, abrangendo-se.

Para os autores, o desenvolvimento se dá a partir das relações que o sujeito estabelece com os outros indivíduos e recursos em cada um dos sistemas. No sistema mais próximo à criança, o microssistema, estão localizadas as pessoas mais presentes em sua rotina, ou seja, inclui a sua família e sua sala de aula.

Os autores apontam que as relações das crianças com o professor, com seus pares e com os materiais são determinantes para seu processo de aprendizagem e reforçam o discurso sobre a dificuldade de analisar esta relação devido à ausência de instrumentos e estratégias de mensuração. E acrescentam que uma classe bem organizada implica em um bom uso, pelo professor, de seu tempo com as crianças, através da estruturação de uma rotina favorável à aprendizagem. A partir de seus estudos, Mashburn e Pianta (2010) concluem que o fator que mais influencia diretamente o desenvolvimento da criança pré-escolar é a qualidade da interação em experiências físicas e sociais das quais a criança participa (o que é mediado pelo professor). As características do professor (nível e tipo de formação) e as características da sala de aula (tamanho da sala e número de alunos por professores) têm uma influência indireta no desenvolvimento da criança, uma vez que elas influenciam diretamente o primeiro fator, a qualidade das interações vividas pela criança. 
Como outros autores que se dispuseram a pensar a questão da interação professor-aluno como essencial para a compreensão de como se dá a aprendizagem, Mashburn e Pianta (2010) defendem, ao concluírem seu artigo, o investimento na formação de professores como alternativa para efetivar o desenvolvimento cognitivo de seus alunos. Entre os aspectos fundamentais desta formação, inclui-se a aprendizagem sobre as melhores formas de interagir com as diferentes idades e o desenvolvimento da capacidade relacional. A partir de nossa própria experiência em salas de aula, na pesquisa acadêmica e na formação de professores, reforçamos esta preocupação sobre a formação docente para uma interação intencional, dialética e eficiente em sala de aula.

\section{Estão os professores preparados para propor interações significativas na sala de aula?}

Compreendendo a importância da intencionalidade da prática docente para a construção de um processo interativo de aprendizagem, cabe indagar: como os professores compreendem a intencionalidade de sua prática? Por esse motivo é tão relevante pensar sobre a formação dos professores, como sinalizam Gatti e Barreto (2009). Como discutimos anteriormente, é função da escola democratizar o acesso ao conhecimento e, como vem apontando a sociologia das desigualdades educacionais, algumas características das unidades escolares podem favorecer a realização desta tarefa de forma mais equitativa. Ao propor uma discussão sobre a relação dialética no processo ensino-aprendizagem, trazemos a reflexão sobre o papel do professor neste processo interativo levando em consideração sua importância frente à democratização do ensino, ou seja, no desafio de garantir que todas as crianças e jovens aprendam.

Esse desafio é tanto maior quanto mais frágil for a formação dos professores. Gatti (2014) aponta alguns problemas na formação de professores, tais como: a formação inicial de professores nos cursos de graduação, ausência de uma política nacional específica para as licenciaturas, aumento da oferta de cursos à distância, características socioeducacionais dos estudantes, evasão nos cursos, entre outros. Neste aspecto é importante lembrar que a legislação brasileira admite como formação inicial do professor, para a atuação na educação infantil e nas séries iniciais do ensino fundamental, o curso médio de nível técnico na modalidade normal (conforme Art. 62 da Constituição Federal, atualizada pela Lei n 12.796 de 2013 [BRASIL, 2013]). 
Tabela. Proporção de docentes atuando na Educação Básica por grau de formação. Brasil, 2015-2019.

\begin{tabular}{lcccccc}
\hline Atuação & Formação & 2015 & 2016 & 2017 & 2018 & 2019 \\
\hline \multirow{2}{*}{ Educação } & Ensino Médio ou inferior & 28,2 & 27,1 & 24,3 & 21,9 & 23,8 \\
Infantil & Superior em andamento & 8,8 & 8,6 & 8,5 & 8,1 & -- \\
& Superior completo & 63,1 & 65,3 & 67,1 & 69,3 & 76,3 \\
Ensino & Ensino Médio ou inferior & 19,7 & 18,5 & 17,3 & 15,3 & 15,8 \\
Fundamental & Superior em andamento & 6,6 & 6,6 & 6,5 & 6,3 & -- \\
Anos Iniciais & Superior completo & 73,7 & 75,0 & 76,2 & 78,5 & 84,2 \\
Ensino & Ensino Médio ou inferior & 9,9 & 9,3 & 8,8 & 7,9 & 8,7 \\
Fundamental & Superior em andamento & 6,0 & 6,1 & 6,0 & 5,5 & -- \\
Anos Finais & Superior completo & 84,0 & 84,7 & 85,3 & 86,7 & 91,4 \\
& Ensino Médio ou inferior & 3,1 & 2,7 & 2,6 & 2,8 & 3,1 \\
\multirow{2}{*}{ Ensino Médio } & Superior em andamento & 4,1 & 4,1 & 3,9 & 3,3 & -- \\
& Superior completo & 92,7 & 93,2 & 93,5 & 93,9 & 96,8 \\
\hline
\end{tabular}

Nota: * Em 2019, o Censo Escolar parou de coletar cursos superiores em andamento.

Fonte: Produzido pelas autoras com dados do Censo Escolar da Educação Brasileira (INSTITUTO NACIONAL DE ESTUDOS E PESQUISAS EDUCACIONAIS ANÍSIO TEIXEIRA, 2020)

Embora se perceba um avanço nos últimos anos no que se refere à formação inicial dos docentes no território nacional, ainda cabe preocupação quanto à distribuição desta porcentagem por nível de atuação (Tabela). Em 2015, 36,9\% dos professores da educação infantil e 26,3\% dos professores dos anos iniciais do ensino fundamental não haviam concluído o ensino superior. Em 2019, houve um aumento no grau de formação desses professores, correspondendo a 76,3\% os professores da educação infantil e a $84,2 \%$ os professores dos anos iniciais do ensino fundamental com ensino superior completo. Em 2015, havia mais de 2,1 milhões de professores atuando na educação básica no Brasil, dentre os quais apenas 76,3\% cursaram o ensino superior. Em 2019, esse número passou para 85,3\% em um total de mais de 2,2 milhões de professores, o que significa um aumento de praticamente nove pontos percentuais em apenas quatro anos.

Conforme apontam os dados, a formação inicial dos professores que atuam na Educação Infantil e nos anos iniciais do Ensino Fundamental ainda acontece, em grande número, em cursos técnicos na modalidade normal. A preocupação com o nível de formação dos professores da educação básica é expressa no atual Plano Nacional de Educação (PNE) 2014-2024, em sua Meta 15: 
Garantir, em regime de colaboração entre a União, os Estados, o Distrito Federal e os Municípios, no prazo de 1 (um) ano de vigência deste PNE, política nacional de formação dos profissionais da educação de que tratam os incisos I, II e III do caput do art. 61 da Lei $n^{\circ}$ 9.394, de 20 de dezembro de 1996, assegurado que todos os professores e as professoras da educação básica possuam formação específica de nível superior, obtida em curso de licenciatura na área de conhecimento em que atuam (BRASIL, 2014).

Tal preocupação e investimento se justificam a partir dos dados apresentados acima e considerando a importância da formação docente para os resultados de desempenho de seus alunos. Nesse sentido, cabe destacar que a Resolução nº2/2015 (BRASIL, 2015) considera indispensável para o projeto nacional da educação brasileira a consolidação das normas nacionais para a formação de profissionais do magistério para a educação básica. E entre os princípios desta formação estão a efetiva articulação entre a teoria e a prática no processo de formação docente, bem como um projeto formativo nas instituições de educação sob uma sólida base teórica e interdisciplinar que reflita a especificidade da formação docente e assegure organicidade ao trabalho. Mais importante do que a certificação dos professores para atuarem na educação básica, especialmente nas séries iniciais do ensino fundamental, torna-se necessário refletir sobre como esta formação inicial se traduz em melhoria no processo de ensino e aprendizagem escolares.

De acordo com Earp (2009), os professores, ainda que conheçam bem a disciplina que lecionam, não se responsabilizam pelo fato de seu aluno não aprender, embora tenham cursado pedagogia ou licenciatura. Os docentes justificavam seus modos de agir na sala de aula com frases como: "Eles deveriam saber"; "Não é minha responsabilidade ensinar coisas da base”. Segundo a autora, é como se o aprendizado fosse um dom que alguns recebem e outros não; e parece existir uma crença generalizada de que alguns alunos são menos capazes de aprender. O esforço de se melhorar a qualidade da educação e o desempenho dos estudantes brasileiros deve passar por compreender o processo de ensino por dentro das salas de aula (EARP, 2009).

Mas não basta os professores assumirem o compromisso da docência, é essencial que estejam preparados para isso, e sobre a formação inicial nas licenciaturas, para além das dificuldades já conhecidas, tais como o reduzido espaço para a prática da docência e a expansão dos cursos a distância, está a própria formação dos formadores. Gatti et al. afirmam que não há programas institucionalizados de formação para professores do ensino superior e muitos dos que atuam em cursos de licenciatura não têm preparação pedagógica (GATTI et al., 2019, p. 301). 
Cabe destacar, no entanto, que a presença de um número considerável de professores contratados, nas redes municipais de ensino, afeta a qualidade, não apenas por trazer uma precarização da profissão docente, mas, sobretudo, do ensino. Essa precarização do ensino caminha junto com a descontinuidade do vínculo entre o professor e a formação pedagógica. No Brasil, de acordo com as informações do Instituto Nacional de Estudos e Pesquisas Educacionais Anísio Teixeira (Inep), no ano de 2019, o total de professores não efetivos no ensino fundamental, na rede pública era de $31,6 \%$.

O aumento no número de professores com contrato de trabalho temporário nas redes de ensino constitui uma precarização do trabalho docente que se manifesta em diferentes aspectos, tais como, na baixa remuneração, na desqualificação e fragmentação do trabalho do professor, na perda real e simbólica de espaços de "reconhecimento social”, nas frágeis relações entre gestores e professores, pais e professores, entre outros aspectos que Mancebo (2007) elencou.

Assim, pensar a formação docente para atuar nas interações de aprendizagem de forma significativa passa, como procuramos demonstrar, pela compreensão sobre o nível e a qualidade de sua formação inicial e sobre suas condições/estabilidade de trabalho.

\section{Considerações finais}

Procuramos apresentar, neste trabalho, elementos para a reflexão sobre o processo ensino-aprendizagem, entendendo-o a partir de uma lógica dialética. Neste processo, o papel de mediação do professor tem lugar de destaque. Uma vez que o professor lida com coletividades, ou seja, com grupos de alunos organizados em turmas ou classes, é preciso refletir sobre como estas interações acontecem na sala de aula considerando, especialmente, a equidade no tratamento entre alunos e nas possibilidades de aprendizagem. A qualidade destas interações e o conhecimento sobre as características de seu alunado, acreditamos, são fatores essenciais para a qualidade da atividade docente. Algumas pesquisas apresentadas neste artigo apontam indicações acerca da importância da qualidade desta mediação: ao garantir a participação dos alunos em sala de aula, na escolha de estratégias e recursos adequados à aprendizagem, na construção de relações sociais significativas em sala de aula. Diante de tantos desafios, destacamos a importância de rever a formação de professores, tanto no aspecto de garantir a esses profissionais uma formação inicial em nível superior, quanto 
na preocupação de que esta formação lhes ofereça insumos para a realização de uma prática significativa em sala de aula. A formação docente não pode estar desprovida de reflexão intelectual, e para tanto importa desenvolver uma cultura profissional docente, em que se estabeleça uma sintonia entre teoria e prática. Não se trata de um recuo da prática para que a formação acadêmica prevaleça, nem tampouco que se enfatize a prática docente em detrimento do conhecimento acadêmico. Trata-se de um compromisso político em que todos os envolvidos com a prática pedagógica possam pensar sobre o que a educação poderia ser - o que inclui as condições de trabalho do professor, uma vez que a precarização da profissão docente acarreta a precarização do ensino.

Neste trabalho destacamos a falta de uma definição nacional consensual sobre a formação inicial para professores que atuarão nos anos iniciais da educação básica, criando uma indefinição que, muito provavelmente, agrava as desigualdades educacionais (uma vez que professores mais bem formados tendem a estar alocados nas escolas que apresentam melhores resultados). Para uma análise mais profunda sobre o tema, que nos ajudasse a responder à questão levantada - Estão os professores preparados para propor interações significativas na sala de aula? -, seria necessário analisar as matrizes curriculares e ementas dos cursos de licenciatura, o que foge ao escopo deste trabalho. Cabe, contudo, sinalizar alguns achados de autores que trabalharam nesta direção. Em estudo no qual levantam dados sobre a formação docente em países desenvolvidos e na América Latina, Louzano e Moriconi (2014) destacam a relevância da articulação entre a teoria e a prática na formação docente para uma mediação mais eficiente na sala de aula. O estudo aponta as iniciativas de países como Singapura e Finlândia, onde os cursos de formação docente estabelecem uma estreita relação com práticas escolares. No Brasil, segundo as autoras, as diretrizes para a formação inicial de professores/as definem que "todas as disciplinas que compõem os currículos, não somente as pedagógicas, terão sua dimensão prática, sem explicitar as formas que permitiriam fazê-lo” (LOUZANO, MORICONI, 2014, p. 37, nossa tradução). A articulação entre teoria e prática na formação docente, além de garantir a vivência da práxis docente, traz a possibilidade do/a licenciando/a experimentar situações de interação em um cenário real de sala de aula. Assim, o caminho argumentativo construído ao longo deste trabalho reforça a necessidade de pensarmos uma formação inicial de professores que favoreça, prioritariamente, a relação entre a teoria e a prática em situações em que estes profissionais aprendam a mediar relações de conhecimento em sala de aula. Com as reflexões aqui apresenta- 
das, pretendemos contribuir para o debate educacional, reforçando a relação entre o investimento na formação inicial dos professores e a reflexão sobre a qualidade dos processos de ensino-aprendizagem desenvolvidos na educação básica.

\section{Referências}

ALVES, M. T.; FRANCO, C. A pesquisa em eficácia escolar no Brasil: evidências sobre o efeito das escolas e fatores associados à eficácia escolar. In: BROOKE, N.; SOARES, J. F. (Orgs.). Pesquisa em eficácia escolar: origem e trajetórias. Belo Horizonte, MG: Universidade Federal de Minas Gerais, 2008. p. 482-500.

BRASIL. Constituição Federal. Constituição Federal da República Federativa do Brasil. Brasília, DF: Senado Federal; 1988.

BRASIL. Lei n ${ }^{\circ}$ 9.394, de 20 de dezembro de 1996. Estabelece as diretrizes e bases da educação nacional. Diário Oficial da União. 21 dez. 1996.

. Lei $n^{\circ} 13.005$, de 25 de junho de 2014. Aprova o plano nacional de educação (PNE) e dá outras providências. Diário Oficial da União. 26 jun. 2014.

. Lei $\mathrm{n}^{\circ}$ 12.796, de 4 de abril de 2013. Altera a lei $\mathrm{n}^{\circ}$ 9.394, de 20 de dezembro de 1996, que estabelece as diretrizes e bases da educação nacional, para dispor sobrea formação dos profissionais da educação e dá outras providências. Diário Oficial da União, 5 abr. 2013.

BRASIL. Ministério da Educação. Resolução nº 2, de 1 de julho de 2015. Diretrizes curriculares nacionais para a formação inicial em nível superior (cursos de licenciatura, cursos de formação pedagógica para graduados e cursos de segunda licenciatura) e para a formação continuada. Diário Oficial da União. 2 jul. 2015.

BROOKE, N.; SOARES, J. F. (Orgs.). Pesquisa em eficácia escolar: origem e trajetórias. Belo Horizonte, MG: Universidade Federal de Minas Gerais, 2008.

CASTORINA, J. A. Piaget-Vygotsky: novas contribuições para o debate. 6. ed. São Paulo, SP: Ática, 2002.

CHARLOT, B. Da relação com o saber: elementos para uma teoria. Porto Alegre, RS: ArtMed, 2000.

CORAZZA, S. M. Planejamento de ensino como estratégia de política cultural. In: MOREIRA, A. F. (Org.). Currículo: questões atuais. Campinas, SP: Papirus, 1997. p. 103-43. 
CORREA, E. V.; BONAMINO, A.; SOARES, T. M. Evidências do efeito da repetência nos primeiros anos escolares. Estudos em Avaliação Educacional, São Paulo, v. 25, n. 59, p. 242-69, set./dez. 2014. https://doi.org/10.18222/eae255920142862

CREEMERS, B. P. M.; REEZIGT, G. J. School level conditions affecting the effectiveness of instruction. School Effectiveness and School Improvement, London, v. 7, n. 3, p. 197-228, 1996. https://doi.org/10.1080/0924345960070301

EARP, M. L. S. A cultura da repetência em escolas cariocas. Revista Ensaio: Avaliação de Política Pública Educacional, Rio de Janeiro, v. 17, n. 65, p. 613-32, out./dez. 2009. https://doi.org/ 10.1590/S0104-40362009000400004

FONTANIVE, N.; KLEIN, R. Alguns indicadores educacionais de qualidade no Brasil de hoje. São Paulo em Perspectiva, São Paulo, v. 23, n. 1, p. 19-28, jan./jun. 2009.

GATTI, B. Formação inicial de professores para a educação básica: pesquisas e políticas educacionais. Estudos em Avaliação Educacional, São Paulo, v. 25, n. 57, p. 24-54, jan./abr. 2014. https://doi.org/10.18222/eae255720142823

GATTI, B.; BARRETO, E. S. Professores no Brasil: impasses e desafios. Brasília, DF: Unesco, 2009.

GATTI, B. et al. Professores do Brasil: novos cenários de formação. Brasília, DF: Unesco, 2019.

INSTITUTO NACIONAL DE ESTUDOS E PESQUISAS EDUCACIONAIS ANÍSIO TEIXEIRA - INEP. Censo da educação básica 2019: notas estatísticas. Brasília, DF: Ministério da Educação, 2020.

KLEIN, R. Como está a educação no Brasil? O que fazer? Revista Ensaio: Avaliação $e$ Políticas Públicas Educacionais, Rio de Janeiro, v. 14, n. 51, p. 139-72, abr./jun. 2006. https://doi.org/10.1590/S0104-40362006000200002

KRAMER, S. Por entre as pedras: arma e sonho na escola. 3. ed. São Paulo, SP: Ática, 2003.

KRAMER, S.; SANTOS, T. R. L. Contribuições de Lev Vygotsky para a pesquisa com crianças. In: MARCONDES, M. I.; OLIVEIRA, I. A.; TEIXEIRA, E. (Org.). Abordagens teóricas e construções metodológicas na pesquisa em educação. Belém, PA: Universidade do Estado do Pará, 2011. p. 17-36. 
LOUZANO, P.; MORICONI, G. Visión de la docencia y características de los sistemas de formación docente. In: ORGANIZACIÓN DE LAS NACIONES UNIDAS PARA LA EDUCACIÓN, LA CIENCIA Y LA CULTURA - Unesco. (Org.). Temas críticos para formular nuevas políticas docentes en América Latina y el Caribe: el debate actual. Santiago: Centro de Estudios de Políticas y Prácticas en Educación, 2014. p. 10-52.

MANCEBO, D. Agenda de pesquisa e opções teórico-metodológicas nas investigações sobre trabalho docente. Educação e Sociedade, Campinas, v. 28, n. 99, p. 466-82, maio/ago. 2007. https://doi.org/10.1590/S0101-73302007000200009

MASHBURN, A. J.; PIANTA, R. C. Opportunity in early education: improving teacher-child interactions and child outcomes. In: REYNOLDS, A. J. et al. (Eds.). Childhood programs and practices in the first decade of life: a human capital integration. Cambridge: Cambridge University, 2010. p. 243-65.

MONTEIRO, A. M. F. C. Professores de história: entre saberes e práticas. Rio de Janeiro, RJ: Mauad, 2007.

NUNES-MACEDO, M. S. A.; MORTIMER, E. F.; GREEN, J. A constituição das interações em sala de aula e o uso do livro didático: análise de uma prática de letramento no primeiro ciclo. Revista Brasileira de Educação, Rio de Janeiro, n. 25, p. 18-29, jan./abr. 2004. https://doi.org/10.1590/S1413-24782004000100003

OLIVEIRA, R. P.; ARAÚJO, G. C. Qualidade do ensino: uma nova dimensão da luta pelo direito à educação. Revista Brasileira de Educação, Rio de Janeiro, n. 28, p. 5-23, jan./abr. 2005. https://doi.org/10.1590/S1413-24782005000100002

PATTO, M. H. A produção do fracasso escolar: histórias de submissão e rebeldia. São Paulo, SP: Casa do Psicólogo, 1996.

PRESTES, Z. R. Quando não é quase a mesma coisa: análise de tradução de Lev S. Vygotsky no Brasil: repercussões no campo educacional. 2010. Tese (Doutorado em Educação) — Universidade de Brasília, Brasília, DF, 2010.

RIBEIRO, S. C. A pedagogia da repetência. Estudos Avançados, São Paulo, n. 12, v. 5, p. 7-21, maio/ago. 1991. https://doi.org/10.1590/So103-40141991000200002

SOARES, J. F. Melhoria do desempenho cognitivo dos alunos do ensino fundamental. Cadernos de Pesquisa, São Paulo, v. 37, n. 130, p.135-60, jan./abr. 2007. https://doi.org/10.1590/S0100-15742007000100007 
TACCA, M. C. V. R.; BRANCO, A. U. Processos de significação na relação professor-alunos: uma perspectiva sociocultural construtivista. Estudos de Psicologia, Natal, v. 13, n. 1, jan./abr. 2008. https://doi.org/10.1590/S1413-294X2008000100005

VYGOTSKY, L. S. Pensamento e linguagem. São Paulo, SP: Martins Fontes, 2008. . Psicologia pedagógica. São Paulo, SP: Martins Fontes, 2001. . A construção do pensamento e da linguagem. São Paulo, SP: Martins Fontes, 2009.

WARTOFSKY, M. A construção do mundo da criança e a construção da criança no mundo. In: KOHEN, W. O.; KENNEDY, D. (Org.). Filosofia e infância: possibilidades de um encontro, volume 2. 2. ed. Petrópolis, RJ: Vozes, 1999. p. 89-159.

Submetido em: 20/09/2019

Aceito em: 20/05/2020

\section{Sobre as autoras}

\section{Maria Elizabete Ramos}

Doutoranda do Programa de Pós-Graduação em Educação da PUC-Rio.

E-mail: mbete.ramos@gmail.com

\section{Ana Cristina Prado de Oliveira}

Professora Adjunta da Escola de Educação e do Programa de Pós-Graduação em Educação da Unirio.

E-mail: ana.prado.oliveira@gmail.com 